\title{
A LEI FUNDAMENTAL DA ALEMANHA NOS SEUS 60 ANOS E O DIREITO CONSTITUCIONAL BRASILEIRO: ALGUMAS APROXIMAÇÕES
}

\author{
INGO WOLFGANG SARLET ${ }^{*}$
}

\begin{abstract}
RESUMO: A Lei Fundamental da Alemanha, promulgada em 1949, ao completar sessenta anos em maio de 2009, constitui um dos mais contundentes exemplos de que o modelo do Estado Constitucional pode ser vitorioso. Além disso, por obra da doutrina e da jurisprudência, o direito constitucional alemão ocupa hoje um lugar de destaque na constelação constitucional mundial, exercendo ampla influência sobre outras ordens constitucionais. No presente texto, além de algumas notas sobre a evolução constitucional alemã, serão abordados alguns aspectos da influência da Lei Fundamental sobre a evolução constitucional brasileira.
\end{abstract}

PALAVRAS-CHAVE: Lei Fundamental; Estado Constitucional; Direito Constitucional Brasileiro.

\begin{abstract}
The German Basic Law, put into force in 1949, as it completes sixty years in May, 2009, constitutes one of the most patent examples that the Constitutional State model can succeed. Furthermore, due to the doctrine and jurisprudence's work, the German constitutional law occupies today a spotlight in the world constitutional constellation, exercising broad influence over other constitutional orders. In this text, in addition to some notes on the German constitutional evolution, a few aspects of the Basic Law's influence over the Brazilian constitutional evolution will be addressed.

KEYWORDS: Basic Law; Constitutional State; Brazilian Constitutional Law.
\end{abstract}

SUMÁRIO: I. Notas sobre o "nascimento" e afirmação da Lei Fundamental de Bonn (1949) como Constituição da República Federal da Alemanha; II. Sobre a influência da Lei Fundamental de 1949 sobre a evolução constitucional brasileira.

SUMMARY: I. Notes on the "birth" and affirmation of the Bonn Basic Law (1949) as the Constitution of the Federal Republic of Germany; II. On the 1949 Basic Law's influence over the Brazilian constitutional evolution.

\begin{abstract}
Artigo recebido em 23.05.2009 e aprovado para publicação pelo Conselho Editorial em 23.06.2009.
* Doutor e Pós-Doutor (bolsista do DAAD) em Direito pela Universidade de Munique. Professor Titular da Faculdade de Direito e dos Programas de Mestrado e Doutorado em Direito e em Ciências Criminais da PUCRS. Professor Visitante da Universidade Católica Portuguesa, como bolsista do Programa Erasmus Mundus, da União Européia (Lisboa) e do Doutorado em Direitos Humanos e Desenvolvimento da Universidade Pablo de Olavide, Sevilha. Pesquisador visitante do Instituto Max-Planck de Direito Social Estrangeiro e Internacional (Munique), como bolsista do Instituto. Pesquisador Visitante no Georgetown Law Center e na Harvard Law School. Professor da Escola da AJURIS e Juiz de Direito no RS. Autor das obras A Eficácia dos Direitos Fundamentais, $10^{\mathrm{a}}$ edição, e Dignidade da Pessoa Humana e Direitos Fundamentais na Constituição Federal de 1988, $7^{\mathrm{a}}$ edição, ambas publicadas pela Livraria do Advogado Editora, Porto Alegre.
\end{abstract}




\section{NOTAS SOBRE O “NASCIMENTO” E AFIRMAÇÃO DA LEI FUNDAMENTAL DE BONN (1949) COMO CONSTITUIÇÃO DA REPÚBLICA FEDERAL DA ALEMANHA}

Há sessenta anos, precisamente no dia 23.05.1949, entrou em vigor a Lei Fundamental da República Federal da Alemanha (Grundgesetz), apenas quatro anos após a rendição incondicional das forças armadas alemãs, que formalizou a derrocada da ditadura nacional-socialista, que tanto mal causou a tantas pessoas em tantos lugares, inclusive ao próprio povo alemão. Não foi à toa, portanto, que já no Preâmbulo da Lei Fundamental foi consignada tanto a "consciência da responsabilidade perante Deus e os seres humanos", quanto a vontade de, "servir à Paz Mundial". Igualmente emblemática e vinculada ao contexto histórico, além de sem precedentes no constitucionalismo pretérito (a exceção de algumas manifestações isoladas, mas situadas em outras partes da Constituição e com outra expressão literal) a afirmação, consignada já no primeiro artigo da Lei Fundamental, da intangibilidade da dignidade da pessoa humana, acompanhada do comprometimento do povo alemão com os direitos inalienáveis e invioláveis da pessoa humana. Tal afirmação, de resto, foi também manejada como resposta a um determinado modelo de positivismo jurídico, buscando resgatar a importância de uma ordem de valores não necessariamente adstrita ao direito formalmente positivado.

Curiosamente, embora, em certo sentido, de modo compreensível, não foram os políticos alemães da época os protagonistas do processo constituinte, mas sim os governos de ocupação aliados, com destaque para os EUA, que, no lado ocidental e em virtude da crescente polarização em relação à União Soviética, que havia assumido o controle do lado oriental, julgavam ser imprescindível a criação de um Estado alemão ocidental, o que, por sua vez, implicava a necessidade da elaboração de uma constituição ${ }^{1}$. Certamente um dos fatores que determinou a resistência, pelo menos inicial, ao projeto do governo de ocupação em promover a elaboração de uma Constituição, foi precisamente o receio de que com isto se estaria chancelando a divisão da Alemanha, o que de fato veio a acontecer, embora se saiba que tal divisão não teria sido evitada, por si só, com a recusa em elaborar uma nova Constituição.

Tirante este aspecto, assume relevo, em termos de apreciação da evolução histórica, que inicialmente foi convocada uma comissão de especialistas, que, em agosto de 1948 (na ilha Bávara de Herrenchiemsee), elaborou o anteprojeto que, na etapa seguinte, foi apreciado e aperfeiçoado pelo Conselho Parlamentar, composto por 65 representantes eleitos pelas assembléias estaduais dos estados da zona ocidental de ocupação, instalado em 01.09.1948, e que veio a elaborar e aprovar o texto daquilo que viria a ser uma das ordens constitucionais mais estáveis e influentes de todos os tempos. Também de forma altamente significativa, foi em 08.05.1949 (data da rendição alemã) que o Conselho Parlamentar aprovou o texto da Lei

${ }^{1}$ Decisão em prol da criação de um estado alemão ocidental foi tomada na conferência realizada em Londres, em 06.03.1948, da qual participaram além dos EUA, Inglaterra e França, a Bélgica, a Holanda e Luxenburgo. 
Fundamental, tendo a autorização para a sua promulgação sido concedida, por parte do governo de ocupação, quatro dias depois ${ }^{2}$.

No que diz com a elaboração da Lei Fundamental, há aspectos que, ainda mais se levado em conta a trajetória exitosa subseqüente, chamam a atenção e merecem pelo menos breve registro. O primeiro, diz respeito à pergunta, que não raras vezes foi formulada, em relação ao quanto os governos de ocupação não podem e mesmo devem ser incluídos no rol dos pais da Lei Fundamental. Neste particular, além da provocação do processo constituinte e a dependência da aprovação do texto final por parte das forças de ocupação, também algumas diretrizes foram estabelecidas, notadamente a adoção da forma federativa de estado (é curioso que especialmente França e Inglaterra, ambas estados unitários, insistiram neste ponto, pois um estado federal, segundo sua concepção, seria a garantia de um estado mais fraco), do regime democrático e da garantia das liberdades fundamentais. Por outro lado, a despeito das diretrizes genéricas, não houve interferência direta na elaboração do texto, ao contrário do que ocorreu no caso do Japão, onde o texto da constituição foi literalmente imposto aos japoneses pelos EUA. O outro ponto a ser destacado, diz com a ideia assumida pelos autores da Lei Fundamental de que se tratava de um documento provisório, no sentido de que assim que viesse a ocorrer a reunificação alemã, haveria então de ser elaborada a verdadeira Constituição. Foi precisamente por tal razão que o documento aprovado em 08.05.1949 não foi designado de Constituição, mas de Lei Fundamental, além da previsão, no artigo 146, de que a Lei Fundamental deixaria de vigorar tão logo fosse substituída por uma Constituição aprovada pelo conjunto do povo alemão. Quarenta anos depois, caiu o muro de Berlim e as fronteiras, que para muitos já eram tidas como definitivas, deram lugar ao processo de reunificação. A Lei Fundamental, outrora vista como símbolo da própria divisão, seguiu em vigor, assumindo agora o papel de Constituição da Alemanha unificada, muito embora tal processo tenha sido objeto de forte controvérsia, visto que não faltaram vozes clamando pela convocação de uma Assembléia Constituinte ou mesmo pela realização de uma consulta popular.

A trajetória “existencial” da Lei Fundamental, que hoje ocupa papel de destaque inquestionável e incensurável no panorama constitucional contemporâneo, se já se revelava vitoriosa antes da reunificação, agora alcançou sua expressão máxima, revelando, entre outras virtudes, uma legitimidade praticamente sem precedentes e sem paralelos, o que, por sua vez, demonstra que até mesmo alguma deficiência evidente em termos de legitimação democrática originária (considerados os padrões tidos como ideais), pode, a depender das circunstâncias, vir a ser amplamente compensada mediante um processo de permanente reconstrução da legitimidade. De outra parte, constata-se a oportunidade das lições de Peter Häberle, quando nos fala da necessidade de contínua reafirmação do Estado Constitucional ${ }^{3}$, o que, à evidência, se revela como mais fácil quando se atinge níveis expressivos de confiança da população no projeto constitucional e nas instituições que devem atuar

${ }^{2}$ Cf. Reinhold Zippelius, Kleine Deutsche Verfassungsgeschichte, $7^{\text {a }}$ d., Munique: C.H.Beck Verlag, 2006, p. 153 e ss.

${ }^{3}$ Cf. Peter Häberle, Neue Horizonte und Herausforderungen des Konstitutionalismus, in: EUGRZ 2006, p. 537. 
na sua concretização, especialmente quando se instaura aquilo que, de acordo com a terminologia cunhada na própria Alemanha, passou a ser designado de "patriotismo constitucional”.

Mas se é correto afirmar que um bom texto, suficientemente aberto e representativo dos projetos e anseios de determinada sociedade política, constitui uma das garantias para o sucesso de uma ordem constitucional, também é correto afirmar que sem a correspondente “vontade de Constituição” (Hesse) e sem o labor fecundo dos órgãos constitucionais, com destaque para a jurisdição constitucional (sem que aqui se esteja a desconsiderar o peso da estabilidade econômica e institucional, bem como do processo político), o texto constitucional tende a se tornar obsoleto ou mesmo acaba destituído de normatividade efetiva. É, portanto, um conjunto de diversos fatores que explica o sucesso ou fracasso de uma ordem constitucional, razão pela qual se assume aqui o ônus da simplificação.

O sucesso da Lei Fundamental não se afere, todavia, apenas pelo seu significado para o Estado e para o Povo da Alemanha, mas adquire um sentido mais abrangente, quando se avalia a influência do constitucionalismo alemão contemporâneo sobre outras ordens jurídicas. Neste particular, sem prejuízo da evidente importância da Lei Fundamental para um expressivo número de outros Estados Constitucionais (o que se identifica tanto em termos de direito constitucional positivo, quando tem termos doutrinários e jurisprudenciais), de tal sorte que, juntamente com o constitucionalismo norte-americano, a Lei Fundamental é tida hoje como a Constituição mais influente, em termos de direito comparado, no âmbito da evolução constitucional contemporânea, o que nos move aqui é tecer algumas considerações sobre a influência da Lei Fundamental para o direito constitucional brasileiro, o que constitui o objeto do próximo segmento.

\section{SOBRE A INFLUÊNCIA DA LEI FUNDAMENTAL DE 1949 SOBRE A EVOLUÇÃO CONSTITUCIONAL BRASILEIRA}

Quanto a este ponto, uma primeira constatação poderá ser a de que a importância em termos textuais, ou seja, da transposição para o texto constitucional brasileiro de dispositivos previstos na Lei Fundamental, não é assim tão expressiva. Talvez mesmo o modelo da Constituição de Weimar, de 1919, seja, em termos textuais, até mesmo mais próximo, considerando especialmente a presença de normas definidoras de fins e tarefas estatais em matéria de justiça social, a função social da propriedade, o objetivo de assegurar uma existência digna como ideia-força da ordem constitucional econômica, entre outros, aspectos que já vinham se fazendo presentes no constitucionalismo brasileiro desde a Constituição de 1934. Mas, a despeito da maior ou menor proximidade quanto ao teor literal dos dispositivos constitucionais (até mesmo pelo fato de a falta de identidade absoluta não afastar a influência também neste particular), é no plano da evolução doutrinária e jurisdicional que se pode melhor avaliar a repercussão e a atualidade da ordem constitucional da Alemanha, sob a égide da Lei Fundamental, não apenas, mas também e para o que nos interessa para efeitos deste ensaio, para o constitucionalismo brasileiro pós-1988.

Mesmo na Alemanha, não fosse o labor da doutrina e da jurisdição constitucional, 
seguramente a trajetória não teria sido a mesma no que diz com o prestígio da Lei Fundamental. Por outro lado, não tivessem os autores da Lei Fundamental insistido na criação de uma sólida Jurisdição Constitucional, representada pelo Tribunal Constitucional Federal (Bundesverfassungsgericht), cuja atuação fecunda e amplamente reconhecida na esfera pública, guarda relação com o modo de recrutamento dos Magistrados, mas acima de tudo com um bem construído sistema de competências, na relação com os demais órgãos estatais e com um adequado modelo de controle de constitucionalidade, talvez o resultado, por melhor que seja o texto da Lei Fundamental, tivesse sido substancialmente diverso. Igualmente importante tem sido o papel crítico e criativo da doutrina constitucional, até mesmo em virtude do saudável diálogo e recíproca influência entre a jurisdição constitucional e a Academia, o que se constata tanto pelo criterioso exame da jurisprudência por parte da doutrina, seja pela sensibilidade dos Magistrados do Tribunal Constitucional em relação aos aportes vindos do meio acadêmico, tudo concorrendo para uma relação altamente produtiva, ainda que não isente de tensões.

Também o direito constitucional brasileiro, designadamente no período mais recente, sob a égide da Constituição Federal de 1988 e com maior incidência na última década, tem experimentado uma crescente influência por parte da Lei Fundamental, em especial por força do impacto da doutrina e da jurisprudência constitucional. São vários os fatores que explicam tal fenômeno, não sendo o caso aprofundar tal dimensão. Certo é que a principal porta de entrada para o direito comparado tem sido a receptividade por parte da doutrina e jurisprudência nacional. No plano doutrinário, além de um aumento expressivo de doutoramentos, pós-doutoramentos e pesquisas realizados por brasileiros na Alemanha, também se constata um crescimento considerável no que diz com o número de obras de direito constitucional da Alemanha traduzidas para o português, o espanhol e o italiano, que, de forma compreensível, são (ainda) as línguas estrangeiras mais citadas no meio acadêmico nacional, juntamente com o francês e o inglês. A própria importação indireta de categorias do direito constitucional alemão, por meio da doutrina portuguesa, espanhola e italiana, igualmente bastante receptiva à produção alemã, ocupa um lugar de destaque neste processo. Com efeito, atualmente, bastaria um olhar sobre o direito comparado, para que se possa afirmar que a doutrina e jurisprudência constitucional alemãs, notadamente sob a égide da Lei Fundamental, têm contribuído decisivamente para a gradativa construção de uma gramática constitucional comum (pelo menos em alguns campos sensíveis do direito constitucional) ou do que alguns têm designado de um direito constitucional comum. Que o Brasil acabaria de algum modo sendo afetado por tal movimento, ainda mais considerando o perfil do projeto constitucional de 1988, já era de se esperar. Vejamos, portanto, alguns aspectos a respeito de o quanto e como tem operado este diálogo.

Para além da importância inequívoca da doutrina constitucional alemã para a teoria da Constituição de um modo geral, é seguramente no campo da teoria e práxis dos direitos fundamentais e da jurisdição constitucional e do sistema de controle de constitucionalidade, sem prejuízo dos importantes contributos em outras áreas (federalismo, ordem econômica e social, etc.) que se situam os pontos de contato mais importantes e onde mais se tem processado o fenômeno da importação de categorias oriundas ou mais desenvolvidas no direito constitucional alemão. 
Se tomarmos como referência apenas a cada vez mais difundida aceitação da dupla dimensão objetiva e subjetiva dos direitos fundamentais, acompanhada das suas respectivas funções e conseqüências jurídicas, recepcionada também pelo STF, já se justificaria uma resposta afirmativa à indagação sobre o "se" da influência da Lei Fundamental sobre a ordem constitucional brasileira.

Neste particular - da dimensão objetiva dos direitos fundamentais como categoria difundida no constitucionalismo brasileiro - podem ser destacados pelo menos três desenvolvimentos, que comprovam o elevado grau de influência já apontado: a) a inserção, na esfera da assim designada constitucionalização do Direito, do problema da eficácia dos direitos fundamentais nas relações privadas, mediante recurso direto à doutrina e jurisprudência alemãs, embora trilhando caminho substancialmente diverso, visto que, no Brasil, prevalece o entendimento em prol de uma eficácia em princípio direta; b) A recepção - mais recente - da noção de deveres de proteção estatais e da correlata proibição de proteção insuficiente (ou deficiente, como preferem alguns), já aplicada pelo Supremo Tribunal Federal; c) A crescente aposta na assim designada dimensão organizatória e procedimental dos direitos fundamentais e seus diversos reflexos, em particular mediante a aplicação de tal perspectiva ao processo civil, sem prejuízo de avanços em outras searas.

A sempre criticada, mas necessária e saudável - salvo ajustes importantes, designadamente no que diz com o rigor metodológico - difusão da aplicação, no plano do controle das restrições de direitos fundamentais, do princípio da proporcionalidade, tal qual compreendido na dogmática alemã (como exigindo um controle da adequação, necessidade e proporcionalidade em sentido estrito) e da correlata noção - técnica da ponderação, como critério de solução de conflitos entre direitos fundamentais, igualmente merece destaque. Da mesma forma, merece menção a noção da necessária salvaguarda do núcleo essencial como outro limite dos limites em matéria de direitos fundamentais, assim como o controle das emendas constitucionais na base das assim designadas “cláusulas pétreas", por sua vez também associado à proteção do assim designado núcleo essencial dos direitos fundamentais.

Também a relevância da distinção, no plano da dimensão subjetiva, entre a dimensão prestacional e defensiva (apesar da conexão entre ambas as esferas) dos direitos fundamentais, assim como as teorizações e aplicações, ainda que muitas vezes distorcidas (o que evidentemente não ocorre apenas entre nós) a respeito do princípio da dignidade da pessoa humana e do assim chamado mínimo existencial, não poderiam ser relegadas a um plano secundário, visto que amplamente utilizadas na esfera jurisprudencial, mas em especial no âmbito da doutrina constitucional brasileira. Também em matéria de direitos sociais (e não apenas na seara de um mínimo existencial) a influência alemã é manifesta, seja para efeitos de aplicação das categorias já referidas, seja na utilização (nem sempre adequada) de formulações como a "reserva do possível“", a noção de proibição de retrocesso social, dentre outras, todas inquestionavelmente incorporadas ao debate nacional. Da mesma forma, a qualificação da discussão sobre outros aspectos ligados aos direitos fundamentais, como é o caso da titularidade por parte das pessoas jurídicas, da tutela após a morte, assim como sobre o regime jurídico dos direitos de personalidade, seja de forma 
direta, seja mediante a leitura de autores de outros países, constituem frentes onde se revela de forma particularmente evidente a influência alemã.

Em plano conexo, visto que sem o fortalecimento da jurisdição constitucional e do sistema de controle de constitucionalidade, boa parte dos aspectos já citados teriam tido impacto consideravelmente menor, pode ser situada a relevância, para o Brasil, do "modelo germânico" de jurisdição constitucional. Aqui também, não fosse o intenso labor de importantes setores da doutrina, que impulsionaram a inserção gradativa de elementos do sistema germânico, boa parte das importantes conquistas, seguramente não apenas no que diz com a importação de categorias e institutos do direito constitucional alemão, talvez não tivessem sido possíveis ou pelo menos não da forma como vieram a ocorrer. Basta citar a previsão do amicus curiae, da técnica da interpretação conforme a constituição e suas variações, da manipulação dos efeitos na esfera do controle de constitucionalidade, da categoria do processo objetivo (ainda que nem sempre bem compreendida e manejada), para que se perceba a extensão e o caráter praticamente permanente (embora ajustes de rota seguramente venham a ocorrer) da influência do constitucionalismo de matriz germânica entre nós.

Não sendo nosso propósito esgotar a relação de tópicos onde se manifesta com particular agudeza a influência da Lei Fundamental (considerada no seu conjunto, incluindo a evolução doutrinária e jurisprudencial) entre nós, um breve balanço se impõe. Com efeito, ao que tudo indica, se a avaliação, em termos de um juízo de valor positivo ou negativo, tende seguramente a pender em favor da primeira alternativa, visto que inquestionável a qualificação do debate jurídico-constitucional no Brasil a partir da consideração dos aportes oriundos da Alemanha, também é certo que segue correta a percepção, cada vez mais compartilhada entre nós, de que uma importação direta e acrítica de categorias argumentativas e institutos jurídicos estrangeiros, sem a devida filtragem e contextualização, muitas vezes resulta em distorções que devem ser evitadas.

O que se espera é que o diálogo Brasil-Alemanha siga fecundo, ganhando em qualidade crítico-reflexiva, de tal sorte que a comemoração dos sessenta anos da Lei Fundamental possa ser um símbolo de que a afirmação gradativa do modelo do Estado Constitucional (portanto, do Estado Democrático de Direito) constitui de fato uma tendência irreversível. 